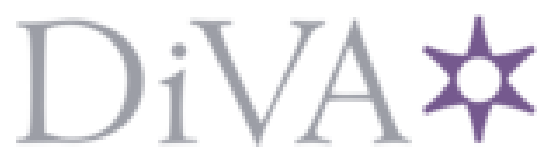

http://www.diva-portal.org

This is the published version of a paper published in Zeitschrift für Naturforschung $C-A$ Journal of Biosciences.

Citation for the original published paper (version of record):

Eiras, A E., Kovaleski, A., Vilela, E F., Chambon, J P., Unelius, C R. et al. (1999)

Sex pheromone of the Brazilian apple leafroller, Bonagota cranaodes Meyrick

(Lepidoptera, Tortricidae)

Zeitschrift für Naturforschung C - A Journal of Biosciences, 54(7-8): 595-601

https://doi.org/10.1515/znc-1999-7-822

Access to the published version may require subscription.

N.B. When citing this work, cite the original published paper.

Permanent link to this version:

http://urn.kb.se/resolve?urn=urn:nbn:se:lnu:diva-14114 


\title{
Sex Pheromone of the Brazilian Apple Leafroller, Bonagota cranaodes Meyrick (Lepidoptera, Tortricidae)
}

\author{
Alvaro E. Eiras ${ }^{\mathrm{a}, *}$, Adalecio Kovaleski ${ }^{\mathrm{b}}$, Evaldo F. Vilelac ${ }^{\mathrm{c}}$, Jean P. Chambon ${ }^{\mathrm{d}}$, \\ C. Rikard Unelius ${ }^{\mathrm{e}}$, Anna-Karin Borg-Karlson ${ }^{\mathrm{e}}$, Ilme Liblikas ${ }^{\mathrm{e}}$, \\ Raimondas Mozuraitis ${ }^{\mathrm{e}}$, Marie Bengtsson ${ }^{\mathrm{f}}$ and Peter Witzgall ${ }^{\mathrm{f}}$ \\ a Departamento de Parasitologia - ICB/UFMG, Universidade Federal de Minas Gerais, \\ Cx.P. 486, Belo Horizonte, MG, 31270-901 Brazil. Fax: +55 314992970. \\ E-mail: alvaro@mono.icb.ufmg.br \\ b Departamento de Entomologia, CNPUV/EMBRAPA, 25200-000, Vacaria, RS, Brazil \\ c Departamento de Biologia Animal, Universidade Federal de Viçosa, 36.570-000, Viçosa, \\ MG, Brazil \\ d INRA, Station de Zoologie, 78026 Versailles Cedex, France \\ e Department of Chemistry Organic, Royal Institute of Technology, 10044 Stockholm, \\ Sweden \\ f Department of Plant Protection Sciences, Swedish University of Agricultural Sciences, \\ 23053 Alnarp, Sweden \\ * Author for correspondence and reprint requests \\ Z. Naturforsch. 54c, 595-601 (1999); received February 24/March 3, 1999 \\ Sex Pheromone, (3E,5Z)-3,5-dodecadienyl Acetate, Bonagota cranaodes,
}

Brazilian Leaf Roller, Tortricidae

The female sex pheromone of Bonagota (=Phthteochroa) cranaodes (Meyrick) is a blend of $(E, Z)$-3,5-dodecadienyl acetate $(E 3, Z 5-12: A c)$ and $(Z)$-9-hexadecenyl acetate $(Z 9-16: A c)$ according to analysis of pheromone - gland extracts and field trapping in apple orchards. This is the first time that $E 3, Z 5-12$ :Ac has been identified as a lepidopteran sex pheromone. Traps baited with $100 \mu \mathrm{g} E 3, Z 5-12$ :Ac were attractive over 15 weeks in the field and were as effective as traps baited with virgin females. Addition of $Z 9-16$ : Ac to E3,Z5-12:Ac at ratio of $1: 10$ had a significantly increase of male moths. The addition of the $Z, E$ and $Z, Z$ isomers to rubber septa baited with $E 3, Z 5-12$ :Ac did not modify $B$. cranaodes male attraction, but $10 \%$ of $E E$ enhanced trap catch.

\section{Introduction}

During the last decade, the production of apple in Southern Brazil has increased to $350,000 \mathrm{t} / \mathrm{yr}$ and to an area of 30,000 ha (Kovaleski, 1992). The Brazilian apple leaf roller, Bonagota (Phtheochroa) cranaodes Meyrick, is besides Anastrepha fruit flies the most important pest of apple in Southern Brazil and Uruguay. It accounts, despite intensive insecticide spraying, for an annual crop loss of 3 to $5 \%$, corresponding to approx. US\$ 10 million/yr. The damage is done by third- to fifthinstar larvae feeding on the fruit skin; the larvae shelter effectively between fruit and leaves and are therefore difficult to control by insecticides (Eiras et al., 1992; Eiras et al., 1994; Kovaleski, 1992).

There is considerable interest to develop a monitoring system based on a synthetic pheromone lure, as outbreaks of $B$. cranaodes occur throughout the growing season and this necessitates fre- quent insecticide sprays. Traps baited with live virgin females have been used so far, but the development of a synthetic lure is required for routine use. In view of the exposure of the work force to insecticides and their destabilizing effect on the orchard ecosystem, it is our future goal to develop safe control of $B$. cranaodes by mating disruption (Cardé and Minks, 1995; Ridgway et al., 1990; Witzgall and Arn, 1997).

Occurrence of a female-produced sex pheromone in $B$. cranaodes was first documented by Eiras et al. (1993); the main pheromone component has been identified as $(E, Z)-3,5$-dodecadienyl acetate (E3,Z5-12:Ac) (Unelius et al., 1996). We here report on a detailed identification of compounds produced in female sex glands and first field trapping tests. 


\section{Methods and Materials}

Insects

The laboratory population originates from apple orchards in Vacaria (RS, Brazil). Larvae were reared on a semi-synthetic diet at the Federal University of Viçosa (Eiras et al., 1994; Parra et al., 1995). Sexed pupae were shipped to Sweden for gland extraction and chemical analysis. The emerging adults were kept in plexiglass cages $(30 \times 30 \times 30 \mathrm{~cm})$ at $23{ }^{\circ} \mathrm{C}, 65 \% \mathrm{RH}$ and a $14 \mathrm{~L}: 8 \mathrm{D}$ photophase.

\section{Collection of pheromone from calling female moths}

Extracts of pheromone glands from 2 to 4-dayold females were made during the first hr of the calling period. Glands were excised with forceps and stored in a glass vial held in liquid air. After dissection of female glands in batches of up to 35 , the vial was defrosted and $5 \mu \mathrm{l}$ of redestilled hexane was added under $1 \mathrm{~min}$. The solvent was removed with a syringe and injected on a gas chromatograph coupled to a mass-selective detector (GC/MS).

Headspace solid phase microextraction (SPME) was done according to Zhang and Pawliszyn (1993) and Borg-Karlson and Mozuraitis (1996). Prior to collection and after injection, the SPME fiber was heated in a GC injector at $225^{\circ} \mathrm{C}$ for $10 \mathrm{~min}$. The tip of the syringe with the cleaned SPME fiber $(100 \mu \mathrm{m}$ polydimethylsiloxane) was kept a few millimeters from the protruded abdominal gland of a virgin calling female in a glass vial $(30 \times 70 \mathrm{~mm}$, volume $30 \mathrm{ml})$, during $2-3$ hours at $18{ }^{\circ} \mathrm{C}$. The female was then removed and hexane solutions of heptyl acetate (10 ng) and pentadecadecyl acetate (100 ng) were added to the glass vials as internal standards and adsorbed during $15 \mathrm{~min}$. Peaks from non-calling and calling females were compared $(\mathrm{N}=6)$.

\section{Gas chromatography and GC-mass spectrometry} (GC and GC-MS)

Gland extracts were analyzed on a Varian 3400 gas chromatograph (GC) interfaced with a Finnigan SSQ 7000 mass spectrometer (MS). Two fused silica capillary columns, a DB-5 and a DBWax $(30 \mathrm{~m}$, i.d $0.25 \mathrm{~mm}$, film thickness $0.25 \mathrm{~mm}$;
$\mathrm{J} \& \mathrm{~W}$, Folsom, California), were used with a temperature programme of $80^{\circ} \mathrm{C}(1 \mathrm{~min}$ hold $), 6{ }^{\circ} \mathrm{C} /$ $\min$ to $140{ }^{\circ} \mathrm{C}$, and $3{ }^{\circ} \mathrm{C} / \mathrm{min}$ to $200{ }^{\circ} \mathrm{C}$. Mass spectral data and retention times of selected peaks on both columns were compared to corresponding data from reference standards.

\section{Gas chromatography and electroantennographic} detection (GC-EAD)

Two gland extracts were analyzed by GC-EAD. The outlet from a DB-Wax column in a Hewlett Packard 5870A GC was split between a flame ionization detector (FID) and an apparatus for recording of electroantennograms (EAG; Syntec, Hilversum, The Netherlands). Male antennae of $B$. cranaodes were used for these tests.

\section{Synthesis of 3,5-dodecadienyl acetates}

The $E, Z$ and $E, E$ isomers $(E 3, Z 5-12 A c$ and $E 3, E 5-12: A c)$ were synthesized via a WadsworthHorner-Emmons condensation reaction of methyl 4-dimethylphosphonocrotonate (2) with octanal (Baeckström et al., 1988) and subsequent deconjugation by lithium diisopropylamine and diisobutylaluminium hydride (DIBAL) reduction (Ikeda $e t$ al., 1987) as the key steps (Fig. 1). The alcohols formed by reduction of the 3,5-dodecadienoates with DIBAL were acetylated and the $E, Z$ - and $E, E$-isomers were separated by liquid chromatography on silver nitrate impregnated silica gel. The $Z 3, Z 5-12 \mathrm{Ac}$ was synthesized by a route involving a Cadiot-Chodkiewicz coupling reaction of 3-butyn-1-ol with 1-bromo-1-octyne (6), and dicyclohexylborane reduction of 3,5-dodecadiyn-1-ol (7) as the key steps (Svirskaya and Leznoff, 1980). The Z3,E5-12Ac was prepared via a synthesis route involving the coupling reaction of 3-butyn1-ol and (E)-1-octenyl iodide (9) in the presence of a catalytic amount of $\mathrm{Pd}(\mathrm{PPh} 3) 4$ under phase transfer conditions (Rossi et al., 1982) followed by a $(Z)$-stereoselective reduction of the triple bond in the $(E)$-enyne acetate (11) using a $\mathrm{Zn}-\mathrm{Cu}$ couple as the reducing agent (Sondengam et al., 1980).

\section{Field tests}

Trap tests were done in apple orchard in Vacaria (RS, Brazil). White Delta sticky traps (AgriSense, Pontypridd, UK) were baited with red rubber 

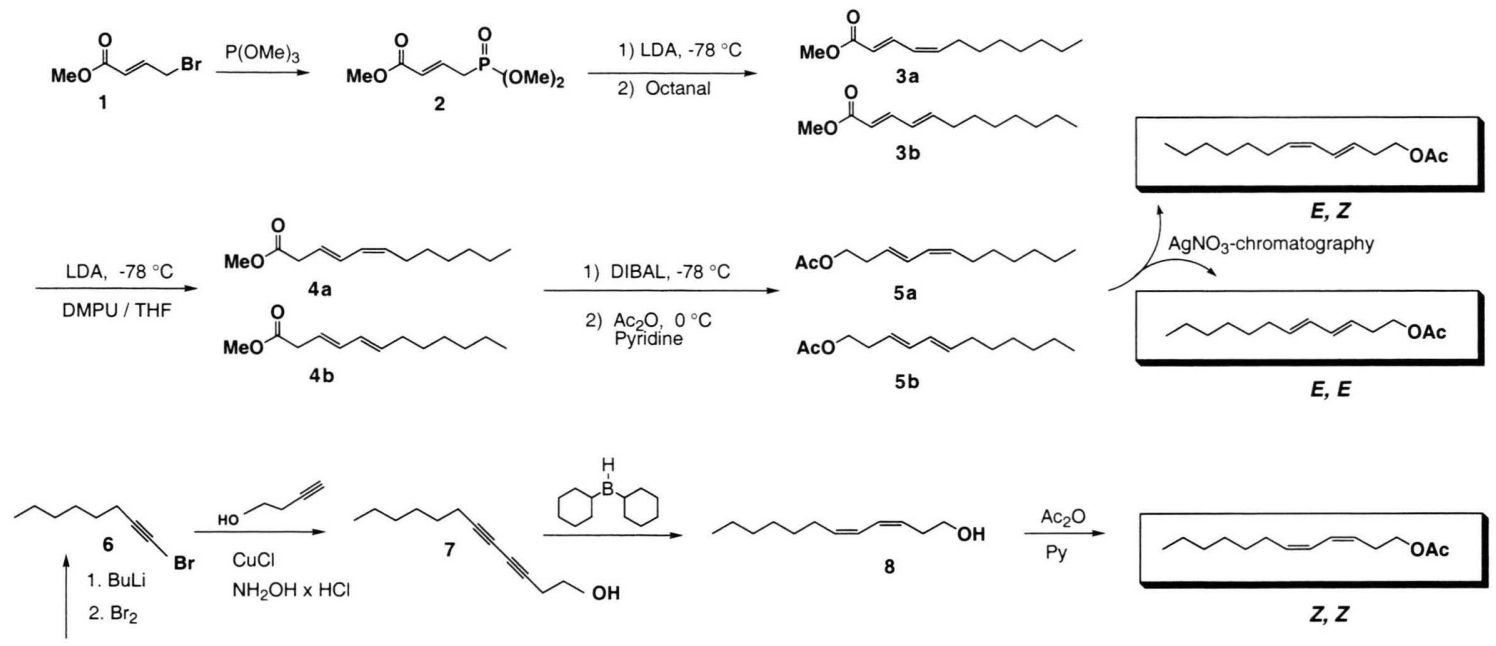

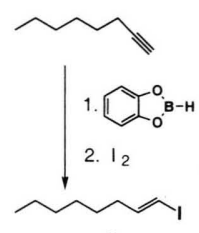

9
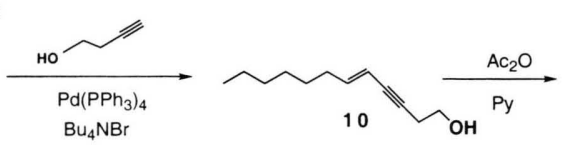

Fig. 1. Synthesis of geometric isomers of 3,5-12Ac.

septa (ABS, Dietikon, Switzerland). Test chemicals were formulated as hexane solutions. Two caged virgin female moths were used as control. The isomers of $3,5-12 \mathrm{Ac}$ were isomerically $>98 \%$ and chemically $>99 \%$ pure, the monoenic $(E)-3-$ dodecenyl acetate (E3-12:Ac), (Z)-3-dodecenyl acetate $(Z 3-12$ :Ac), $(Z)$-5-dodecenyl acetate $(Z 5-12: A c)$ and $(E)-5$-dodecenyl acetate (E512:Ac) were purchased from Dr. Simon Voerman (Wageningen Agricultural University, The Netherlands) and were isomerically $>99 \%$ pure.

Traps were hung on apple trees at ca. $2 \mathrm{~m}$ height, and separated from one another by $20-$ $30 \mathrm{~m}$. Traps were deployed in a randomized block design with treatments. Traps were controlled and re-randomized within blocks every 2 to 3 days. Data were transformed to $\log (x+1)$ prior analysis of variance and means were separated using the Tukey test $(P=0.05)$. The first experiment tested the supposed main candidate pheromone component. The E3,Z5-12:Ac and those dodecenyl acetates which elicited positive EAG responses on the male antennae were loaded in red septa and tested alone $(100 \mu \mathrm{g})$ and in combinations. The second experiment tested the two compounds found in the gland extract which elicited electrophysiological responses on the males antennae (E3,Z512:Ac and Z9-16:Ac) to confirm the main compound of the sex pheromone. The third experiment tested the dose-response of the main compound which caught more insect from the second experiment at 1,10 and $100 \mu \mathrm{g} / \mathrm{septum}$. The fourth experiment tested the binary combinations of the main compound $(50 \mu \mathrm{g})$ in combination with the secondary compound at the ratios of 1:0.1, 1:1, $1: 10$ and $1: 100$. The ratios of equivalent amount of $0 ; 5 ; 50 ; 500$ and $5,000 \mu \mathrm{g} / \mathrm{septa}$, respectively, was loaded in grey rubber septa. The fifth experiment tested the effect of isomers on the main sex pheromone compound.

\section{Results}

\section{Taxonomy}

The Brazilian apple leaf roller has been described as Phtheochroa cranaodes (Meyrick, 1931) and this name has been used until now by Brazilian entomologists. However, the species belongs now, according to a recent revision of neotropical Archipini, to the newly described genus Bonagota 
(Razowski, 1986). B. cranaodes had been erroneously treated as Eulia salubricola (Meyrick, 1937) by Uruguayan entomologists. Examination of the wing pattern and genitalia of male insects collected in orchards in Uruguay (leg. Persoons) and Southern Brazil (leg. Eiras) showed that the species causing damage in apple in both countries is actually $B$. cranaodes.

\section{Chemical analysis of gland extracts}

Analysis of gland extracts by GC-MS showed the presence of a number of acetates (Table I), whereas the SPME-collection of calling females gave only one peak. A GC-EAD analysis of two female gland extracts revealed two active compounds: a very strong antennal response was obtained for $E 3, Z 5-12 \mathrm{Ac}$ and weaker response for Z9-16Ac.

The mass spectrum of E3,Z5-12Ac had two characteristic features (Fig. 2). The fragments 79, 80 and 164 (M-60) gave very high peaks, while the molecular ion 224 was quite weak $(<1 \%)$. The absence of an $\mathrm{M}+$ peak indicated that the loss of the acetate group was facilitated and that the unknown acetate was homoallylic or allylic. The fragment 164 would be formed after an initial McLafferty rearrangement and a subsequent charge migration followed by a alpha cleavage. The strong characteristic peaks 79 and 80 looked like highly unsaturated molecular ions $\left(\mathrm{C}_{6} \mathrm{H}_{7}\right.$ and $\left.\mathrm{C}_{6} \mathrm{H}_{8}\right)$ which also indicated that the double bonds were positioned close to the acetate group. With this in mind we synthesized a mixture of 2,4- and 3,5decadienyl acetates. The mass spectra of the 2,4isomers showed high $\mathrm{M}+$ ion peaks, while the mass spectra of the 3,5-isomers were very similar to the one of our unknown acetate. Therefore, the synthesis of 3,5-dodecadienyl acetate was undertaken.

Table I. Pheromone-related compounds identified in $B$. cranaodes females by GC and GC/MS.

\begin{tabular}{lll}
\hline Compound & Short Form & ng/female \\
\hline Decyl acetate & $10 \mathrm{Ac}$ & 0.8 \\
Dodecyl acetate & $12 \mathrm{Ac}$ & 1.6 \\
E3,Z5-Dodecadienyl acetate & E3,Z5-12Ac & 7.0 \\
Tetradecyl acetate & $14 \mathrm{Ac}$ & 1.0 \\
Hexadecyl acetate & $16 \mathrm{Ac}$ & 11.1 \\
Z9-Hexadecenyl acetate & Z9-16Ac & 23.1 \\
Octadecylacetate & $18 \mathrm{Ac}$ & 100 \\
\hline
\end{tabular}
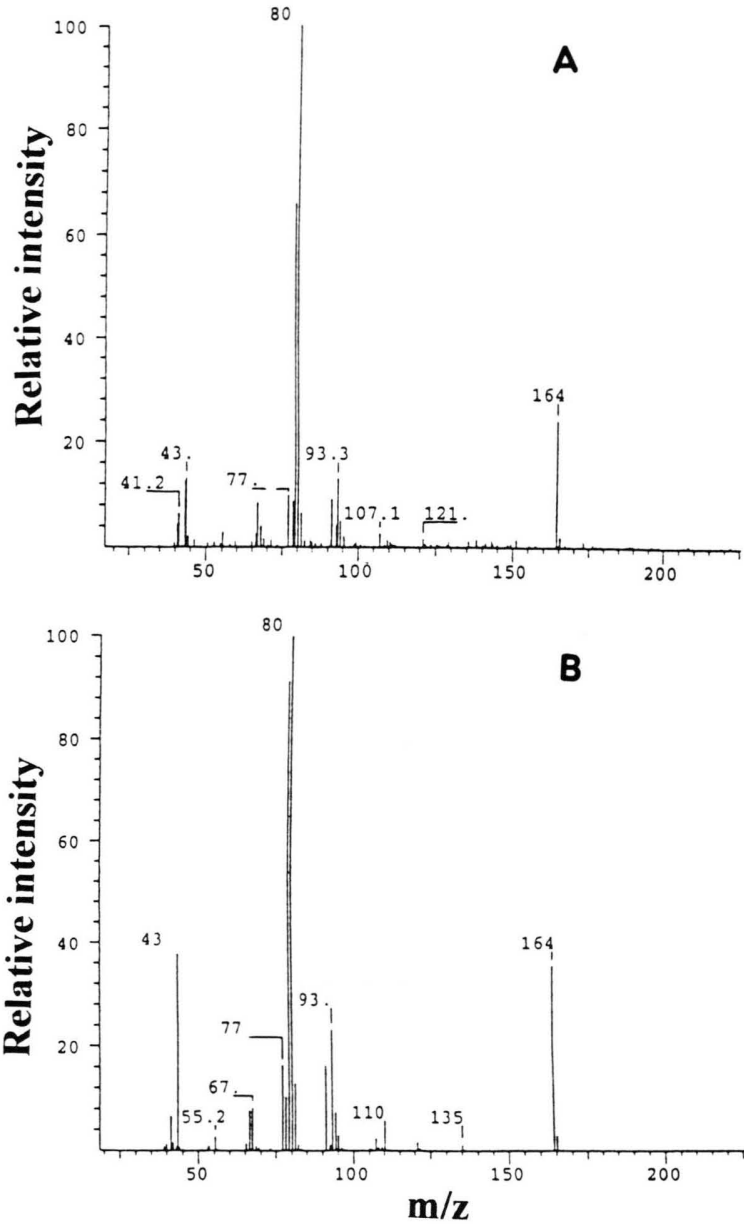

Fig. 2. Electron impact mass spectrum of E3,Z5-12Ac. (a) SPME and (b) reference E3,Z5-12Ac.

The gland extract was coinjected with an isomer mixture on two GC columns with different polarity. The unknown compound co-eluted with synthetic E3,Z5-12Ac from both columns.

\section{Field trapping}

Synthetic E3,Z5-12Ac, at a dose of $100 \mu \mathrm{g}$, was as attractive as traps baited with virgin females (Table II) and can thus be used for monitoring of $B$. cranaodes. The $A 33$ - and $A 5$-monounsaturated dodecenyl acetates were completely unattractive (Table II). In another orchard, a dose-response test with $0,1,10$ and $100 \mu \mathrm{g} E 3, Z 5-12 \mathrm{Ac} /$ trap attracted $0 ; 7 \pm 1.4 ; 12.5 \pm 2.4$ and $7.5 \pm 1.1$ males/ trap, respectively $(N=7)$, over a period of six weeks. 
Table II. Field attraction of B. cranaodes males to virgin females, synthetic main pheromone compound and 3- or 5 -unsaturated dodecenyl acetates (Tukey test, $P=0.05$ ).

\begin{tabular}{lcr}
\hline Trap lure & $\begin{array}{c}\text { Amount } \\
{[\mu \mathrm{g}]}\end{array}$ & $\begin{array}{r}\text { Males caught } \\
(\text { Mean } \pm \text { s.e. })\end{array}$ \\
\hline Virgin female & & $39.3 \pm 8.0 \mathrm{~b}$ \\
$E 3, Z 5-12 \mathrm{Ac}$ & 100 & $38.7 \pm 8.0 \mathrm{~b}$ \\
$E 3-12 \mathrm{Ac}$ & 100 & $0 \pm 0 \mathrm{a}$ \\
$Z 3-12 \mathrm{Ac}$ & 100 & $0 \pm 0 \mathrm{a}$ \\
$E 5-12 \mathrm{Ac}$ & 100 & $0 \pm 0 \mathrm{a}$ \\
$Z 5-12 \mathrm{Ac}$ & 100 & $0 \pm 0 \mathrm{a}$ \\
$E 3-12 \mathrm{Ac}+Z 3-12 \mathrm{Ac}$ & $100+100$ & $0 \pm 0 \mathrm{a}$ \\
$Z 3-12 \mathrm{Ac}+Z 5-12 \mathrm{Ac}$ & $100+100$ & $0 \pm 0$ \\
\hline
\end{tabular}

The traps catches of male moths were significantly increases when Z9-16:Ac was added to $E 3, Z 5-12 \mathrm{Ac}$ in the ratio of $1: 1$ in the lure. No increased of catches of $B$. cranaodes was observed at any other ratio (Table III).

Dienic pheromone compounds are known to isomerize quickly on rubber septa used for field trapping (Brown and McDonough, 1986). We therefore tested the effect of the other, nonpheromonal isomers in binary blends with the main compound, E3,Z5-12Ac (Table IV). Interestingly, none of the isomers had an antagonistic effect on trap catch except the amount of $50 \mu \mathrm{g}$ of $E 3, E 5$ 12Ac. Addition of $5 \mu \mathrm{g}$ of the $E, E$-isomer had a possible synergistic effect.

\section{Discussion}

The sex pheromone of the Brazilian apple leaf roller, B. cranaodes is E3,Z5-12Ac, according to chemical analysis of female sex glands and field trapping tests with synthetic compounds. This compound has not been identified as tortricid sex pheromone before, but has been reported as sex attractant in a gelechiid species, Chionodes lugubrella (Reed et al. 1985; Arn et al., 1992; 1999). B. cranaodes belongs to the tortricid tribe Archipini where the most common structure of sex pheromones identified consist of monounsaturated dodecenyl acetates with the double bonds in position 9 or 11 . However, the Archipini tribe is polyphyletic and sex pheromones of neotropical species have not been studied.

Synthetic E3,Z5-12Ac, at a dose of $100 \mu \mathrm{g}$, is an effective lure (Table II) and can be used for monitoring of $B$. cranaodes populations in the field. The other isomers had very little effect on male attraction, and isomerization of E3,Z5-12Ac

Table III. Attraction of male Bonagota cranaodes to Delta trap baited with E3,Z5-12Ac or binary combinations with Z9-16Ac. Nova Escocia Orchard, Vacaria (RS, Brazil). Tukey test, $P=0.05$ ).

\begin{tabular}{|c|c|c|c|}
\hline 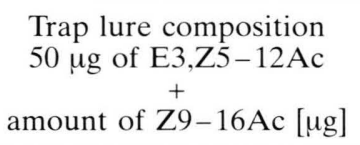 & $\begin{array}{l}\text { Number of males caught } \\
\text { (Mean } \pm \text { s.e. })\end{array}$ & $\begin{array}{l}\text { Number of } \\
\text { males caught } \\
\text { Total }\end{array}$ & $(\mathrm{N})$ \\
\hline 0 & $24.76 \pm 2.95 \mathrm{c}$ & 619 & 25 \\
\hline 5 & $5.52 \pm 3.50 \mathrm{a}$ & 388 & 25 \\
\hline 50 & $36.36 \pm 3.79 \mathrm{~d}$ & 909 & 25 \\
\hline 500 & $19.16 \pm 5.66 b c$ & 479 & 25 \\
\hline 5000 & $12.64 \pm 2.25 \mathrm{~b}$ & 316 & 25 \\
\hline
\end{tabular}

Table IV. Field attraction of $B$. cranaodes males to virgin females, and blends of the synthetic main pheromone compound $E 3, Z 5-12 \mathrm{Ac}$ with its geometric isomers $E E, Z E, Z Z(\mathrm{~N}=30$; Tukey test, $P=0.05)$.

\begin{tabular}{ccccc}
\hline $\begin{array}{c}E 3, Z 5-12 \mathrm{Ac} \\
{[\mu \mathrm{g}]}\end{array}$ & $\begin{array}{c}E 3, E 5-1212 \mathrm{Ac} \\
{[\mu \mathrm{g}]}\end{array}$ & $\begin{array}{c}Z 3, E 5-12 \mathrm{Ac} \\
{[\mu \mathrm{g}]}\end{array}$ & $\begin{array}{c}Z 3, Z 5-12 \mathrm{Ac} \\
{[\mu \mathrm{g}]}\end{array}$ & $\begin{array}{c}\text { Males caught } \\
(\text { Mean } \pm \mathrm{s}, \mathrm{e} .)\end{array}$ \\
\hline 50 & - & - & - & $25.9 \pm 5.14 \mathrm{ab}$ \\
50 & 5 & - & - & $31.9 \pm 5.93 \mathrm{~b}$ \\
50 & 50 & - & - & $15.3 \pm 3.98 \mathrm{a}$ \\
50 & - & 50 & - & $27.1 \pm 4.08 \mathrm{ab}$ \\
50 & - & - & 5 & $20.4 \pm 5.65 \mathrm{ab}$ \\
50 & - & - & 50 & $27.6 \pm 5.65 \mathrm{ab}$ \\
50 & - & &
\end{tabular}


in the traps will therefore not decrease the attractivity of lures. In comparison, isomerization of conjugated dienes formulated on rubber septa used for field trapping is known to deteriorate trap catch (McDonough et al., 1990; Witzgall et al., 1993) and monitoring traps for pea moth are therefore baited with a monoene, E10-12Ac, which mimics the dienic pheromone, E8,E1012Ac (Wall, 1988). In B. cranaodes, the Æ3- and Æ5-monounsaturated dodecacenyl acetates were completely unattractive (Table II).

Although female glands contained about threefold amounts of Z9-16Ac, relative to E3,Z5$12 \mathrm{Ac}$ (Table I), trap catch with binary blends of these two compounds seemed to peak at a 1:10 ratio (Table III). In collections of female effluvia by the SPME technique, Z9-16Ac was not detected, whereas male antennae responded during GC-EAD analysis of gland extracts to this compound. Further studies on the sex pheromone release by $B$. cranaodes females and behavioral studies should be carried out in order to elucidate a potential behavioral role of this compound.

Arn H., Tóth M. and Priesner E. (1992), List of Sex Pheromones of Lepidoptera and Related Attractants. $2^{\text {nd }}$ Edition. International Organization for Biological Control, Montfavet.

Arn H., Tóth M. and Priesner E. (1999), List of Sex Pheromones of Female Lepidoptera and Related Male Attractants. Internet edition. http://www-pherolist.slu.se.

Baeckström P., Jacobsson U., Norin T. and Unelius C. R. (1988), Synthesis and characterization of all four isomers of methyl 2,4-decadienoate for an investigation of the pheromone components of Pityogenes chalcographus. Tetrahedron 44, 2541-2548.

Brown D. F. and McDonough L. M. (1986), Insect sex pheromones: formulations to increase the stability of conjugated dienes. J. Econ. Entomol. 79, 922-927.

Borg-Karlson A.-K. and Mozuraitis R. (1996), Solid phase micro extraction technique used for collecting semiochemicals. Sorption of volatiles released by individual signalling Phyllonorycter moths. Z. Naturforsch. 51c, $599-602$.
Synthetic E3,Z5-12Ac is currently used in experimental programs by Brazilian apple growers for monitoring the flight period and abundance of $B$. cranaodes, in order to time insecticide treatments. Experiments aiming the development of the mating disruption technique for environmentally safe control of this major pest of apple are currently carried out in orchards in Brazil. Further behavioral investigations of the effect of the geometric isomers and other, minor gland components need to be done under controlled conditions in the wind tunnel.

\section{Acknowledgements}

We thank Leslie R. K. Delmore for maintaining the insect cultures. This study was supported by CNPq (Brazilian Government) and by AGAPOMI, the Foundation for Strategic Environmental Research (MISTRA), the International Foundation for Science (IFS), Swedish Council for Agriculture (STFR) and Carl Trygger Foundantion which is gratefully acknowledged.

Cardé R. T. and Minks A. K. (1995), Control of moth pests by mating disruption: successes and constraints. Annu. Rev. Entomol. 40, 559-585.

Eiras A. E., Kovaleski A., Vilela E. F., Souza C. E. P., Frighetto R. S. F., Frighetto N. and Delmore L. R. K. (1992), Observações preliminares sobre a ocorrência de parasitismo natural na lagarta enroladeira Phtheochcroa cranaodes (Lepidoptera: Tortricidae) em pomares de macieira em Vacaria. Simp. Control. Biol. 3, 304.

Eiras A. E., Kovaleski A., Vilela E. F., Frighetto R. S. F. and Frighetto N. (1993), Comportamento de chamamento da fêmea de Phtheochroa cranaodes (Lepidoptera, Tortricidae) e extração do ferômonio sexual. Cong. Brasil. Entomol. 14, 86.

Eiras A. E., Delmore L. R. K., Parra J. R. P., Pique M. P. R., Vilela E. F. and Kowaleski A. (1994), Biologia comparada da lagarta enroladeira Phtheochroa cranaodes Meyrick (Lepidoptera: Tortricidae) em duas dietas artificiais. An. Soc. Entomol. Brasil 23, $251-257$. 
Ikeda Y., Ukai J., Ikeda N. and Yamamoto H. (1987), Selective proton transfer of unsaturated esters. Synthesis of a trail-following pheromone for subterranean termites and megatomoic acid. Tetrahedron 43, 743-753.

Kovaleski A. (1992), MIP fruteiras de clima temperado. In: Manejo Integrado de Pragas e Nematóides (O. A. Ferandes, A. C. B. Correia, and S. A. Bortoli eds.). UNESP, Jaboticabal, pp. 271-287.

McDonough L. M., Eikenbary R. D., Smith M. T., Davis H. G., Smithhisler C. L., Hedger G.A, Campbell R. K., Payne J. A., Reid W. and McVay J. R. (1990), Sex pheromone of hickory shuckworm Cydia caryana. Development of an effective field lure. J. Chem. Ecol. 16, $317-324$.

Meyrick E. (1931), Exotic Microlepidoptera 4. Taylor \& Francis, London, pp.1-642.

Meyrick E. (1937), Exotic Microlepidoptera 5. Taylor \& Francis Ltd., London, pp. 1-160.

Parra J. R. P., Eiras A. E., Haddad M. L., Vilela E. F. and Kovaleski A. (1995), Técnica de criação de Phtheochroa cranaodes Meyrick (Lepidoptera: Tortricidae) em dieta artificial. Rev. Brasil. Biol. 44, 537-543.

Razowski J. (1986), Desriptions of new neotropical genera of Archipini and rectification of the Deltinea problem (Lepidoptera: Tortricidae). Sciences Nat. Bull. 52, 21-25.

Reed D. W. and Chisholm M. D. (1985), Attraction of moth species of Tortricidae, Gelechiidae, Geometridae, Drepanidae, Pyralidae, and Gracillariidae families to field traps baited with conjugated dienes. J. Chem. Ecol. 11, 1645-1657.

Ridgway R. L., Silverstein R. M. and Inscoe M. N. (1990), Behavior-modifying Chemicals for Insect Management: Applications of Pheromones and Other Attractants. Marcel Dekker, New York.
Rossi R., Carpita A., Quirici M. G. and Gaudenzi M. L. (1982), Insect sex pheromones. Palladium-catalyzed synthesis of aliphatic 1,3-enynes by reaction of 1-alkynes with alkenyl halides under phase transfer conditions. Tetrahedron 38, 631-637.

Svirskaya P. I. and Leznoff C. C. (1980), A stereoselective synthesis of a cis, cis conjugated dienol, a candidate pheromone. Synth. Commun. 10, 391-397.

Sondengam B. L., Charles G. and Akam, T. M. (1980), A novel stereospecific reduction of alkynes to alkenes. Tetrahedron Letters. 21, 1069.

Unelius R. C., Eiras A. E., Witzgall P., Bengtsson M., Kovaleski A., Vilela E. F. and Borg-Karlson A-K. (1996), Identification and synthesis of the sex pheromone of Phtheochroa cranaodes (Lepidoptera: Tortricidae) Tetrahedron Lett. 37, 1505-1508.

Wall C. (1988), Application of sex attractants for monitoring the pea moth, Cydia nigricana (F.) (Lepidoptera: Tortricidae). J. Chem. Ecol. 14, 1857-1866.

Witzgall P., Bengtsson M., Unelius C. R. and Löfqvist J. (1993), Attraction of pea moth Cydia nigricana F. (Lepidoptera: Tortricidae) to female sex pheromone $(E, E)-8,10$-dodecadien-1-yl acetate, is inhibited by geometric isomers $(E, Z),(Z, E)$ and $(Z, Z)$. J. Chem. Ecol. 19, 1917-1928.

Witzgall P. and Arn H. (1997), Technology Transfer in Mating Disruption. IOBC wprs Bulletin Vol. 20(1), Montfavet.

Zhang Z. and Pawliszyn J. (1993), Headspace solid phase microextraction. Anal. Chem. 65, 1843-1852. 